\title{
Multiorgan failure with fatal outcome after stem cell tourism
}

\author{
Željka Večerić-Haler ${ }^{1,3^{*}} \mathbb{0}$, Špela Borštnar ${ }^{1,3}$, Boštjan Luzar², Maja Jerše ${ }^{2}$ and Nika Kojc ${ }^{2}$
}

\begin{abstract}
Background: Unproven stem cell treatments may involve serious health, personal, and financial considerations. Due to worldwide spread, illegal stem cell therapies have become a major public health problem. We have already witnessed numerous reports in the mass media of severe and occasionally even fatal outcomes after such therapies. However, there are only few scientifically documented cases in which the causality between stem cell therapy and side effects cannot be refuted.

Case presentation: Here we present a case report of a 48-year-old patient with serious side effects, including disseminated skin ulcers, hepatitis, and cardiomyopathy, with eventual fatal outcome following unproven stem cell treatment.

Conclusions: The case of the patient presented here draws attention to the worst possible outcome of stem cell tourism. To effectively combat this issue, professionals and patients should be empowered with the right knowledge on possible side effects.
\end{abstract}

Keywords: Stem cell, Stem cell tourism, Unproven stem cell treatment, Hepatitis, Skin ulcer, Calciphylaxis, Cardiomyopathy, Multiorgan failure

\section{Introduction}

Patients suffering from various serious conditions can become desperate when conventional medicine fails to provide a solution for their disease. In recent years, there have been a growing number of predatory clinics that have begun advertising unproven therapies at great cost to the patient-this is now referred to as "stem cell tourism" [1]. Many advertised treatments are clinically unproven, frequently presented as being helpful in most debilitating conditions, with little or no evidence of their actual safety and efficacy. Most of such treatments are autologous cellular therapies (patients' own cells are used), although some clinics also claim to use allogenic cord blood, or embryonic and fetal cells. However, it is hard to know what is actually being administered to

\footnotetext{
${ }^{*}$ Correspondence: zeljka.veceric@gmail.com

${ }^{1}$ Department of Nephrology, University Medical Centre Ljubljana, Ljubljana, Slovenia

Full list of author information is available at the end of the article
}

recipients. There are reports of severe side effects and even fatal outcomes after such unregulated interventions [2]. Herein, we present a case report of a patient with serious side effects and eventual fatal outcome following unproven stem cell treatment.

\section{Case report}

A 48-year-old man with end-stage kidney failure, on maintenance dialysis since 2011, was referred in February 2020 with a 6-month history of general malaise and progressive evolvement of painless icterus and necrotizing skin ulcers.

The patient's medical history included diabetes mellitus (DM) type I with end-stage kidney failure, ischemic cardiomyopathy (obstructive lesions of left anterior descending coronary artery resolved by stent placement in 2018), and signs of predominantly diastolic heart failure (ultrasound of the heart prior to the occurrence of the symptoms referred to herein showed a $49 \%$ ejection

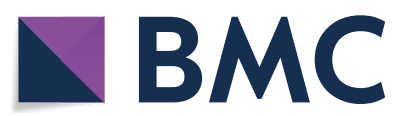

(c) The Author(s) 2021. This article is licensed under a Creative Commons Attribution 4.0 International License, which permits use, sharing, adaptation, distribution and reproduction in any medium or format, as long as you give appropriate credit to the original author(s) and the source, provide a link to the Creative Commons licence, and indicate if changes were made. The images or other third party material in this article are included in the article's Creative Commons licence, unless indicated otherwise in a credit line to the material. If material is not included in the article's Creative Commons licence and your intended use is not permitted by statutory regulation or exceeds the permitted use, you will need to obtain permission directly from the copyright holder. To view a copy of this licence, visit http://creativeco mmons.org/licenses/by/4.0/. The Creative Commons Public Domain Dedication waiver (http://creativecommons.org/publicdomain/ zero/1.0/) applies to the data made available in this article, unless otherwise stated in a credit line to the data. 
fraction, mild mitral and aortic regurgitation, and moderate pulmonary hypertension with $47 \mathrm{mmHg}$ ). His official therapy consisted of lacidipine, furosemide, acetylsalicylic acid, calcium carbonate, bisoprolol, sevelamer, and pantoprazole, and was substantially unchanged in the last year.

In December 2018, the patient underwent stem cell transplantation in Ukraine. The stem cell clinic NBS/ $\mathrm{ICH} / \mathrm{Kiev} /$ London promised--as cited from the brochure, with many grammatical errors»...it is expected strengthening of the regenerative abilities of the body, improving of all functions of organs and tissues and repairing of pathologically damaged tissues, rejuvenate body... « The patient explained he mostly hoped for restitution of his kidney function. Although the patient could not provide an exact operative report, he explained that the product was supposed to be stem cells of embryonal origin and was injected in a single infusion in his peripheral vein. The stem cell clinic claimed in their informative material that examination (including determination of normal heart, lungs, kidney and liver function, as well as ruling out infection) would be performed. However, the patient could not recall any preadmission testing.

At the current referral, jaundice (bilirubin $142 / 116 \mu \mathrm{mol} / \mathrm{l}$, increased alkaline phosphatase, slightly elevated alanine aminotransferase) and necrotizing skin changes predominated in the clinical picture (Fig. 1a, b). He described his skin wounds as aching and itching. The first skin lesions appeared 6 months after stem cell treatment, starting as bullae, which then burst, and a scab formed underneath. The wounds spread all over the body, the most severely affected being the skin on the arms and legs. A deep-punch skin biopsy disclosed segmental medial basophilic calcification with focal atrophy of smooth muscle in media, intimal fibroplasia of smalland/or medium-sized arteries and arterioles in subcutaneous adipose tissue consistent with calciphylaxis. Additional staining with von Kossa highlighted subtle calcium deposits also in the interstitium of the dermis and elastic fibers. Inflammation was relatively scant as well as extravasation of erythrocytes. There were no
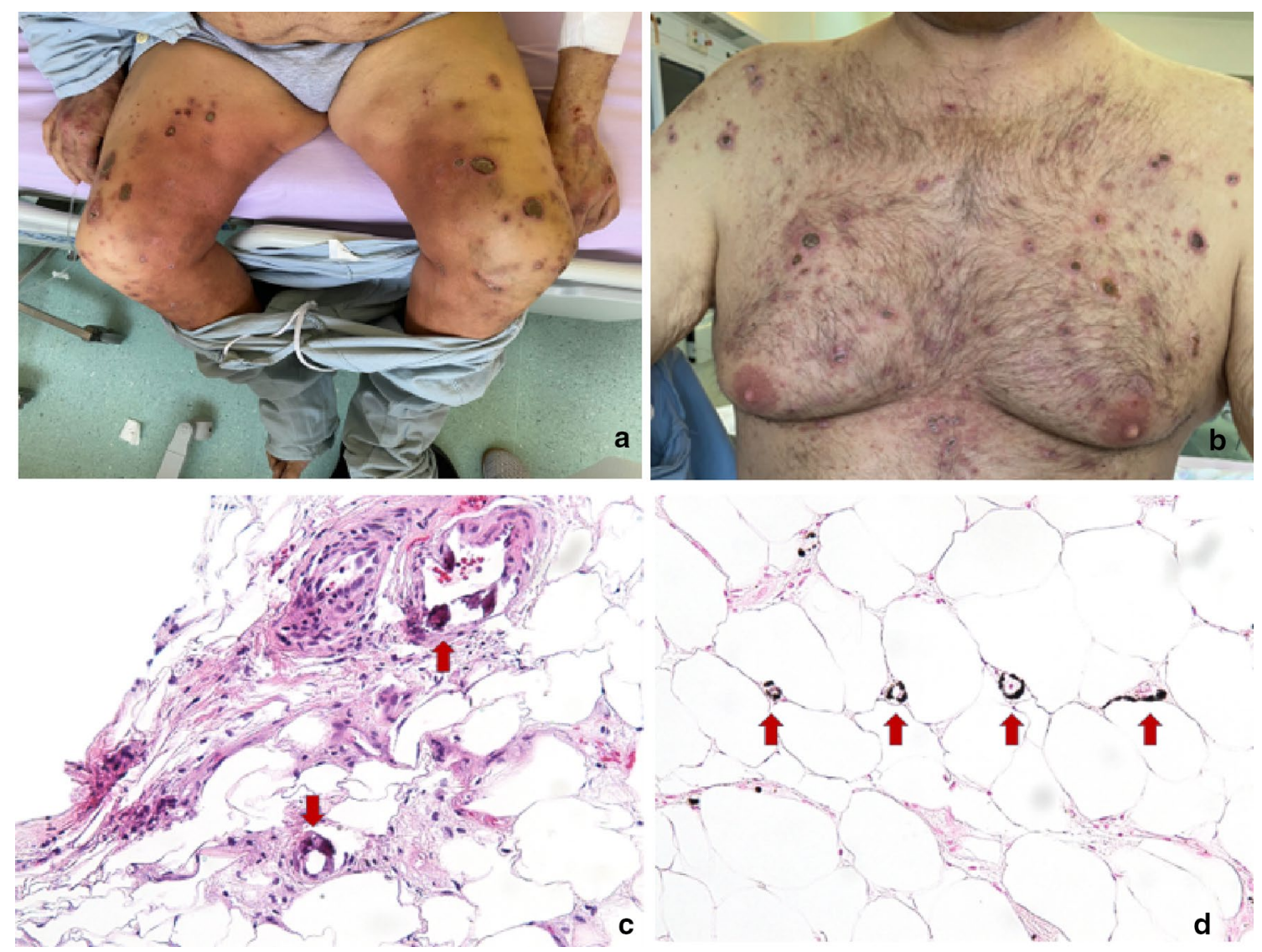

Fig. 1 a, b Necrotizing skin ulcers on the patient's legs and trunk; c Skin biopsy. Basophilic calcification in smooth muscle cells of subcutaneous artery and arteriole (HE, original magnification, 200 ×); d von Kossa stain highlights subtle calcium deposits in arterioles and also in the interstitium of the subcutis (original magnification, $200 \times$ ). Calcifications around vessels and in the interstitium are marked with arrows 
changes suggestive for graft versus host disease (Fig. 1c, d).

However, the pathohistological diagnosis of calciphylaxis was not consistently supported by clinical findings, as there was no severe deterioration of phosphate/calcium metabolism on admission, parathyroid hormone was within limits, and, according to the angiologist's clinical assessment and ultrasound Doppler measurements of perfusion pressure in the lower extremity arteries, macrovascular peripheral arterial disease was not likely.

The first laboratory signs of icterus were present in September 2019. Investigations of icterus included transabdominal and endoscopic ultrasound, which showed hepatosplenomegaly without signs of extrahepatic cholestasis. The most likely infectious, metabolic and autoimmune causes, as well as biliary obstruction (see Additional file 1: Table S1) were ruled out. Since the patient also experienced severe deterioration of heart function in the same time frame (heart ultrasound revealed a severe reduction of the left ventricular ejection fraction to $30 \%$, segmental contraction disorders, rightsided heart failure, and moderate mitral regurgitation), the differential diagnosis included liver congestion due to heart failure of unknown etiology (acute coronary syndrome was ruled out). This was not, however, supported by the liver histology (Fig. 2a, b), which revealed subacute hepatitis with portal inflammation of mixed type (mainly neutrophilic and eosinophilic granulocytes) without convincing signs of chronic liver congestion. We concluded that the hepatic impairment was probably the result of combined liver defect: chronic congestive hepatopathy (dilated sinusoids and ultrasound dilated hepatic veins) and toxic injury of idiosyncratic type, which manifested as cholestatic hepatitis, revealed by liver biopsy. A reasonable trigger for this reaction was, however, unclear and difficult to identify.
In accordance with assumed calciphylaxis, treatment with sodium thiosulfate, intensified dialysis, and hyperbaric oxygen were initiated. The inflammatory parameters decreased, and the patient was cardiopulmonary compensated, with better but not normal laboratory results (bilirubin $45 / 45 \mu \mathrm{mol} / \mathrm{l}$ ) and with slight improvement in skin condition. He insisted on dismission and continued with regular dialysis thrice weekly at our outpatient service. Four days after dismission he was found dead in his apartment. An autopsy was not performed.

\section{Discussion}

The reported case describes a 48-year-old patient who developed necrotizing skin ulcers (pathohistologically confirmed as calciphylaxis), cholestatic hepatitis, and deteriorating heart failure in the period of 6 months post stem cell transplant at a commercial clinic in Ukraine. He was desperately seeking a cure for end-stage kidney failure and DM type I and the aforementioned clinic had offered an unrealistic assurance that stem cells could improve his health state. He underwent intravenous infusion of stem cells of unknown origin and, according to the patient's report, was not given any immunosuppressive therapy prior to stem cell administration.

Although the patient had a number of pre-existing diseases, we were not able to explain and meaningfully connect his new-onset health problems and medical findings with other pre-existent conditions. After exclusion of infection and metabolic causes, toxic damage of idiosyncratic type, which could manifest as cholestatic hepatitis $[3,4]$ and various types of dermatitis [5], was discussed as a possible diagnosis.

In consideration of the fact that the patient did not have other newly introduced medications, in our opinion this complex multisystem disorder could be associated with the applied non-autologous stem cell product, stem
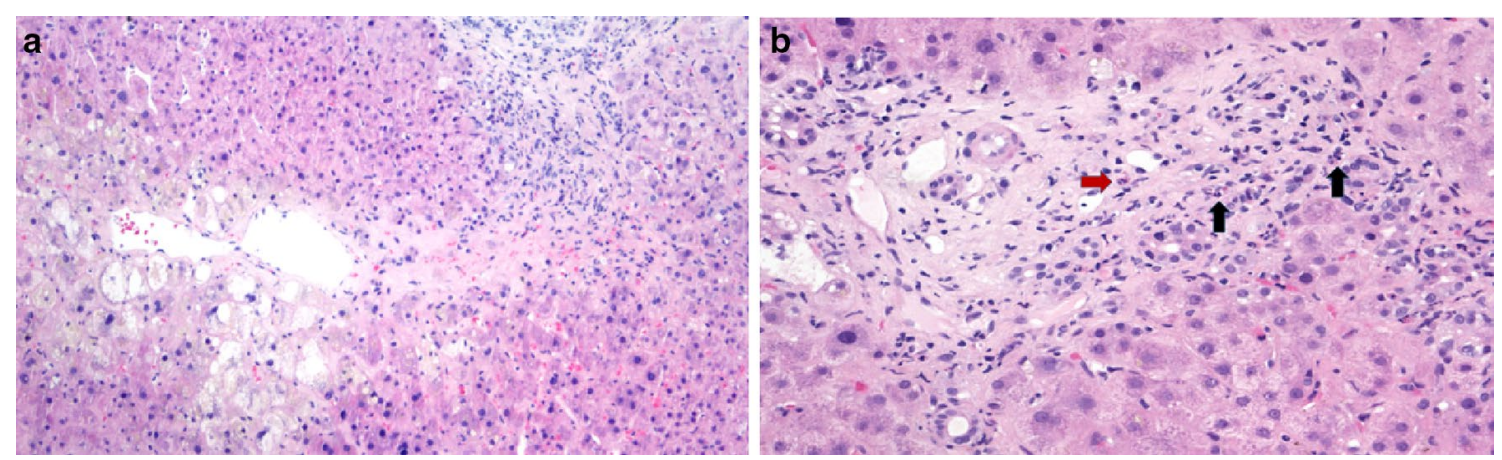

Fig. 2 a Subacute hepatitis with the drop-out of hepatocytes, associated with collapse of hepatic parenchyma, ballooning degeneration of hepatocytes, moderate hepatocellular cholestasis, and mild mixed portal inflammation (HE, original magnification $100 \times$ ). b Liver biopsy, higher magnification of a portal tract. A mixed inflammatory cell infiltrate composed of eosinophils (red arrow) and neutrophils (black arrows) is clearly apparent 
cell medium, or both. Idiosyncratic reactions associated with various substances are characterized by a variable delay or latency period, ranging from a few days to several months from initial exposure to the agent. However, the majority of drug-induced liver injury cases show a steady decline in liver biochemistries after the presumed culprit agent is stopped $[3,4]$. This observation, which is often referred to as "de-challenge" and is a major factor in diagnostic scoring algorithms of drug-induced liver injury, was not observed in our case. Another possibility that we additionally addressed was chronic graft versus host disease (GVHD), a common complication following allogeneic hematopoietic cell transplantation [6]. GVHD may involve a single organ or several organs, but typically manifests as injury to the skin, gastrointestinal mucosa, and liver. In some cases, hepatic GVHD may be histologically indistinguishable from other disorders, such as infection and drug-induced liver injury [7]. A skin biopsy, however, did not confirm histology lesions typical of cutaneous GVHD (interface dermatitis with vacuolar degeneration and lymphocyte satellitosis) [8], but revealed calciphylaxis.

There are several proposed risk factors and triggers for calciphylaxis. In addition to chronic kidney disease and hemodialysis, calciphylaxis could be associated with numerous non-uremic causes (malignancy, hyperparathyroidism, liver disease, skin trauma, autoimmune disorders, certain drugs, and many others). In liver dysfunction, calciphylaxis might be triggered by decreased levels of coagulation inhibitors, decrease of a circulating inhibitor of vascular ossification-calcification and vitamin $\mathrm{K}$ deficiency. Even chronic inflammatory states are possible risk factors since TNF-alpha was shown to induce osteogenic phenotype of human smooth muscle cells [9-11]. Although we have not found a complete explanation for the observed extensive and accelerated formation of small vessels' calcifications, we conclude that in the presented case, besides end-stage renal failure, hepatic impairment may certainly have played an important role [12].

Since we did not have precise information on stem cell type and origin, nor the circumstances in which the cell product was applied, we did not make further analyses and interpretations, in order to avoid any speculation. Nevertheless, the patient demanded discharge from the hospital due to fear at the growing scale of the COVID19 epidemic at the time.

In the present paper, we therefore want to draw attention to two possible major risks of stem cell treatments operating with limited or no regulation: firstly, the possibility of severe multisystem side effects, including severe cardiomyopathy, liver and skin injury, and, secondly, the devastating socio-economic impact on the patient, leaving him financially strapped, with no physical improvement in his condition and no way of reclaiming losses.

\section{Conclusions}

Unproven stem cell treatments may involve serious health, personal, and financial considerations. Regulatory agencies are expected to implement a comprehensive policy and measures clearly to delineate unproven stem cell therapies, which are putting increasing numbers of patients at risk. In cases in which there is a significant potential risk, probably the most effective way to combat this issue is to empower patients with the right knowledge on possible side effects, so allowing them to make an informed decision, and prevent further black scenarios from taking place.

\section{Supplementary Information}

The online version contains supplementary material available at https://doi. org/10.1186/s40001-020-00477-4.

Additional file 1: Table S1. Results of important microbiology, metabolic and serology tests.

\section{Abbreviations}

DM: Diabetes mellitus; GVHD: Graft versus host disease.

\section{Acknowledgements}

The authors would like to thank all the doctors of different specialties who participated in the diagnostic and therapeutic process of the patient's treatment and contributed with their knowledge to the opinion and analysis of the arguments presented in this paper.

\section{Authors' contributions}

ŽVH was a major contributor in writing the manuscript. ŽVH, ŠB, and NK analyzed and interpreted the patient data regarding the whole course of disease. $\mathrm{NK}, \mathrm{BL}$, and $\mathrm{MJ}$ performed the histological examinations and interpretations. All the authors read and approved the final manuscript.

\section{Funding}

This research did not receive any specific grant from funding agencies in the public, commercial, or not-for-profit sectors.

Availability of data and materials

Not applicable.

Ethics approval and consent for publication

The written consent for publication was obtained from patients' family.

Competing interests

The authors declare that they have no competing interests.

\section{Author details}

${ }^{1}$ Department of Nephrology, University Medical Centre Ljubljana, Ljubljana, Slovenia. ${ }^{2}$ Institute of Pathology, Faculty of Medicine, University of Ljubljana, Ljubljana, Slovenia. ${ }^{3}$ Faculty of Medicine, University of Ljubljana, Ljubljana, Slovenia. 
Received: 4 September 2020 Accepted: 28 December 2020

Published online: 09 January 2021

\section{References}

1. Matthews KR, Iltis AS. Unproven stem cell-based interventions and achieving a compromise policy among the multiple stakeholders. BMC Med Ethics. 2015;16(1):75

2. Bauer G, Elsallab M, Abou-El-Enein M. Concise review: a comprehensive analysis of reported adverse events in patients receiving unproven stem cell-based interventions. Stem Cells Transl Med. 2018;7(9):676-85.

3. Chalasani NP, et al. ACG clinical guideline: the diagnosis and management of idiosyncratic drug-induced liver injury. Am J Gastroenterol. 2014;109(7):950-66.

4. Hoofnagle JH, Bjornsson ES. Drug-induced liver injury — types and phenotypes. N Engl J Med. 2019;381(3):264-73.

5. Chung WH, Wang CW, Dao RL. Severe cutaneous adverse drug reactions. J Dermatol. 2016;43(7):758-66.

6. Penack $\mathrm{O}$, et al. Prophylaxis and management of graft versus host disease after stem-cell transplantation for haematological malignancies: updated consensus recommendations of the European Society for Blood and Marrow Transplantation. Lancet Haematol. 2020;7(2):e157-67.

7. Matsukuma KE, et al. Diagnosis and differential diagnosis of hepatic graft versus host disease (GVHD). J Gastrointest Oncol. 2016;7(Suppl 1):S21-31.

8. Strong Rodrigues $\mathrm{K}$, et al. Cutaneous graft-versus-host disease: diagnosis and treatment. Am J Clin Dermatol. 2018;19(1):33-50.

9. Hineno $\mathrm{A}$, et al. Calciphylaxis as a catastrophic complication in a patient with POEMS syndrome. Case Rep Neurol. 2009;1(1):47-53.

10. Nigwekar SU, Thadhani R, Brandenburg VM. Calciphylaxis. N Engl J Med. 2018;379(4):399-400.

11. Nigwekar SU, et al. Calciphylaxis from nonuremic causes: a systematic review. Clin J Am Soc Nephrol. 2008;3(4):1139-43.

12. Sammour YM, et al. Non-uremic calciphylaxis associated with alcoholic hepatitis: a case report. World J Hepatol. 2019;11(1):127-32.

\section{Publisher's Note}

Springer Nature remains neutral with regard to jurisdictional claims in published maps and institutional affiliations.
Ready to submit your research? Choose BMC and benefit from:

- fast, convenient online submission

- thorough peer review by experienced researchers in your field

- rapid publication on acceptance

- support for research data, including large and complex data types

- gold Open Access which fosters wider collaboration and increased citations

- maximum visibility for your research: over $100 \mathrm{M}$ website views per year

At $\mathrm{BMC}$, research is always in progress.

Learn more biomedcentral.com/submissions 